\title{
MACROMYCETES PARKU W MAŁKOCINIE (NW POLSKA)
}

\author{
JUSTYNA KWIATKOWSKA \\ Katedra Botaniki i Ochrony Przyrody, Wydział Biologii, \\ Uniwersytet Szczeciński, \\ ul. Felczaka 3c, 71-412 Szczecin, e-mail: jmlynarczykowksa@gmail.com
}

\begin{abstract}
The paper presents the results of mycological research carried out in the manor Małkocin park (NW Poland) in the years 2008-2009. During 35 observations, 200 species of macromycetes (mainly Basidiomycota - 172 species) and four Myxycomycota have been recorded. Among them, 11 species are included on the red list of macrofungi in Poland. The participation of macrofungi was analyzed in bioecological groups of saprotrophic, mycorrhizal and parasitic fungi. In addition, the comparison of the Małkocin park with other rural parks of Poland is discussed.
\end{abstract}

Keywords: macrofungi, manor park, Western Pomerania, Poland

\section{WSTĘP}

Na terenach wiejskich nierzadko spotkać można założenia parkowe. Wśród parków wiejskich liczną grupę stanowią tzw. parki dworskie, utworzone wokół dawnych posiadłości ziemskich. Gmina Stargard może poszczycić się dużą liczbą tego typu założeń. Parki pałacowe znajdują się m.in. w Barzkowicach, Koszewie, Koszewku, Małkocinie, Skalinie, Strzyżnie, Wierzchlądzie oraz w Pęzinie. Rosną w nich nie tylko rzadkie drzewa i krzewy, często obcego pochodzenia, ale również bardzo stare okazy dębów, buków, lip czy jesionów. Większość z nich powstała jako parki krajobrazowe z elementami naturalistycznymi. Na ich terenie często występują stawy, oczka wodne czy niewielkie strumyki i rzeczki (Sienicka, Kownas 1963; Kownas 1969; Sobisz, Truchan 2010).

Badania składu gatunkowego grzybów wielkoowocnikowych na terenach parków pałacowych były prowadzone w nielicznych regionach Polski, głównie w Wielkopolsce, m.in. w parku w Radojewie (Lisiewska, Ratyńska 1984), Uniejowie (Lisiewska, Rybak 1990), Gołuchowie (Lisiewska, Płaczek 1993) i Turwi (Bujakiewicz, Kujawa 2000). Parki wiejskie gminy Stargard nie były obiektem badań mykologicznych.

Celem niniejszej pracy jest poznanie bogactwa i różnorodności gatunkowej grzybów makroskopijnych parku w Małkocinie oraz określenie udziału i roli grup bioekologicznych grzybów w nim występujących. 


\section{CHARAKTERYSTYKA TERENU BADAŃ}

Park w Małkocinie jest położony w północno-wschodniej części wsi, w gminie Stargard, w odległości około 9 km od Stargardu i około $36 \mathrm{~km}$ od Szczecina. Zajmuje powierzchnię 5 ha. Założony został w połowie XIX w. jako park naturalistyczny z założenia osiowego. Wraz z budynkiem pałacowym tworzy zespół pałacowo-parkowy, który w roku 1977 został wpisany do rejestru zabytków (Kalita 1977). Od roku 2001 właścicielem obiektu jest Wydział Biologii Uniwersytetu Szczecińskiego. Mieści się w nim Centrum Edukacji Środowiskowej.

Małkocin, wraz ze znajdującym się w jego obrębie parkiem, położony jest na granicy Równiny Nowogardzkiej (313.32) z Równiną Pyrzycko-Stargardzką (313.31), które wchodzą w skład makroregionu Pobrzeża Szczecińskiego. Na omawianym terenie zewnętrzną okrywę tworzy gruba powłoka utworów czwartorzędowych o miąższości od $20 \mathrm{~m}$ do $100 \mathrm{~m}$, powstała w wyniku działalności lodowca. W skład tych utworów wchodzą gliny, piaski, żwiry i iły. Poniżej znajdują się utwory trzeciorzędowe, reprezentowane przez piaski drobnoziarniste oraz muły i iły (Mityk 1969; Kondracki 2000).

Rzeźba terenu Małkocina i jego okolic jest bardzo zróżnicowana. Powstała w wyniku działalności lądolodu skandynawskiego podczas ostatniego zlodowacenia bałtyckiego. Omawiany teren leży w obrębie moreny dennej falistej, charakteryzującej się występowaniem równoległych, bochenkowatych pagórków, wałów i obniżeń. Drumliny to płaskie, owalne lub wydłużone pagórki zbudowane z gliny morenowej, które tworzą tzw. stargardzkie pole drumlinowe. W okolicach Małkocina znajduje się również tzw. małkociński wał ozowy, czyli długi, wąski wał przypominający nasyp kolejowy, zbudowany z mułów, piasków i żwirów (Mityk 1969).

Najczęściej spotykanymi glebami okolic Małkocina są bielice i brunatnoziemy, a w dolinach rzek mady. O ich przestrzennej zmienności decydują bochenkowate formy wypukłe pola drumlinowego. Na gliniastych grzbietach i zboczach pagórków występują strefowe gleby brunatnoziemne, u podnóży spotkać można gleby utworzone z osadów deluwialnych, a w zagłębieniach, w zależności od głębokość wód gruntowych, gleby brunatnoziemne, czarne ziemie lub gleby hydrogeniczne (Mityk 1969; Starkel 1999).

Klimat Małkocina i jego okolic charakteryzuje się dość wysoką średnią roczną temperaturą powietrza $\left(8^{\circ} \mathrm{C}\right)$ i niewielką roczną sumą opadów atmosferycznych (550-600 mm). Okres wegetacji roślin trwa około 220 dni. Pokrywa śnieżna zalega średnio 50 dni. Pierwsze przymrozki pojawiają się między 20 i 25 października, a ostatnie między 25 i 30 kwietnia (Woś 1999). W okresie badań mykologicznych średnia temperatura powietrza kształtowała się w granicach $8,62-9,42^{\circ} \mathrm{C}$. Najcieplejszymi miesiącami były lipiec w 2008 r. i sierpień w 2009 r. (tab. 1). Suma opadów atmosferycznych w roku 2008 wynosiła 584,2 mm, a w 2009 644,4 mm (według stacji meteorologicznej Vaisala 
- Helsinki w Szczecinie). Najwięcej opadów w roku 2008 zanotowano w miesiącach kwietniu i październiku, a w 2009 r. w maju, lipcu, sierpniu i październiku (tab. 2). W roku 2008 bardzo ciepłe i suche były miesiące: maj i czerwiec, natomiast w 2009 podobne warunki panowały w kwietniu i wrześniu.

Tabela 1 - Table 1

Średnie miesięczne i roczne temperatury powietrza $\left[{ }^{\circ} \mathrm{C}\right]$ dla stacji meteorologicznej

Vaisala - Helsinki w Szczecinie

Average monthly and annual air temperatures $\left[{ }^{\circ} \mathrm{C}\right]$ for the weather station

Vaisala - Helsinki in Szczecin

\begin{tabular}{|c|c|c|c|c|c|c|c|c|c|c|c|c|c|}
\hline $\begin{array}{l}\text { Lata/miesiące } \\
\text { (Years/months) }\end{array}$ & 1 & II & III & IV & V & VI & VII & VIII & IX & $x$ & $X I$ & XII & $\begin{array}{c}\text { Średnia } \\
\text { roczna } \\
\text { (Annual } \\
\text { average) }\end{array}$ \\
\hline 2008 & 2,4 & 4 & 3,7 & 7,5 & 13,6 & 16,9 & 18,5 & 17,8 & 12,9 & 9,1 & 5,3 & 1,42 & 9,42 \\
\hline 2009 & $-2,28$ & $-0,55$ & 3,49 & 11,31 & 12,39 & 14,44 & 18,54 & 18,62 & 14,22 & 7,21 & 6,61 & $-0,53$ & 8,62 \\
\hline
\end{tabular}

Tabela 2 - Table 2

Sumy miesięcznych i rocznych opadów [mm] dla stacji meteorologicznej

Vaisala - Helsinki w Szczecinie

Total monthly and annual precipitation $[\mathrm{mm}]$ for the weather station

Vaisala - Helsinki in Szczecin

\begin{tabular}{lccccccccccccc}
\hline $\begin{array}{l}\text { Lata/miesiące } \\
\text { (Years/months) }\end{array}$ & I & II & III & IV & V & VI & VII & VIII & IX & X & XI & XII & $\begin{array}{l}\text { Suma } \\
\text { (Total) }\end{array}$ \\
\hline 2008 & 60,71 & 18,29 & 60,45 & 91,44 & 14,22 & 27,94 & 59,44 & 52,32 & 38,86 & 73,91 & 41,66 & 44,96 & 584,2 \\
2009 & 12,45 & 46,23 & 53,09 & 11,43 & 70,61 & 64,77 & 83,82 & 88,39 & 20,32 & 108,71 & 54,86 & 29,72 & 644,4 \\
\hline
\end{tabular}

W obrębie parku znajdują się trzy przepływowe stawy, połączone rowami. Ze stawu zachodniego woda kanałem wpływa do rzeki Małki, która płynie w pobliżu zachodniego ogrodzenia parku i jest prawym dopływem Iny. Na wschodnim stawie znajduje się sztuczna wysepka z drewnianym tarasem i z wypływającym spod niego małym, sztucznym strumykiem. Od omawianego stawu ciągnie się rów w kierunku północnej części parku. Tam, przy sekcji 6, wpływa strumień źródliskowy, który łączy się ze wschodnim stawem. Wysoki poziom wód gruntowych sprawia, że na terenie parku obserwować można wiele wysięków typu źródliskowego (np. w sekcjach 3, 5 i 6). Miejscami podmokłymi są również zachodnie części sekcji 9 i 11, gdzie woda zalega prawie przez cały rok.

W parku dominują drzewa liściaste, głównie: dęby (Quercus spp.), buki ( $F a-$ gus spp.), klony (Acer spp.), graby (Carpinus spp.), jesiony (Fraxinus spp.), wiązy (Ulmus spp.) i olsze (Alnus spp.). Drzew iglastych jest niewiele, przede wszystkim daglezje zielone (Pseudotsuga menziesii) i świerki (Picea spp.). 
Wśród obcych, ozdobnych, hodowlanych gatunków i odmian drzew wymienić można: magnolię pośrednią (Magnolia $\times$ soulangiana), dęba błotnego (Quercus palastium), dęba czerwonego (Q. rubra), jesiona wyniosłego odm. zwisającą (Fraxinus excelsior 'Pendula'), lipę krymską (Tilia 'Euchlora'), lipę amerykańską (T. americana), jodłę kaukaską (Abies nordmanniana), klona jawora f. purpurową (Acer pseudoplatanum f. purpurea), cyprysika groszkowego (Chamaecyparis pisifera) i kasztanowca białego (Aesculus hippocastanum) (Anonymous 2006).

$\mathrm{Na}$ terenie parku występuje również wiele starych i okazałych drzew, w szczególności dębów. Na uwagę zasługują cztery pomniki przyrody: Quercus robur o obwodzie $435 \mathrm{~cm}$, rosnący przy zachodnim boku pałacu (sekcja 12), Fraxinus excelsior o obwodzie $384 \mathrm{~cm}$, znajdujący się w sekcji 12 za pałacem, Fagus sylvatica o obwodzie $454 \mathrm{~cm}$, rosnący przy samym brzegu zachodniego stawu (sekcja 8) oraz Q. robur o obwodzie $420 \mathrm{~cm}$, w pobliżu którego znajduje się miejsce na ognisko (sekcja 9) (Anonymous 2006).

W warstwie krzewów miejscami obficie występują m.in.: śnieguliczka (Symphoricarpos albus), dzika róża (Rosa canina), bez czarny (Sambucus nigra), jaśmin (Jasminum sp.) i podrost robinii akacjowej (Robinia pseudoacacia). Ostatnio posadzono ognik szkarłatny (Pyracantha coccinea), bukszpan (Buxus sempervirens) i wiele innych ozdobnych gatunków, zwłaszcza przed budynkiem pałacowym.

Runo w okresie letnim jest bardzo zwarte, a tworzą je głównie podagrycznik (Aegopodium podagraria) i pokrzywa (Urtica dioica). W miejscach bardziej wilgotnych obserwować można kosaćce (Iris pseudacorus), kukliki (Geum rivale), jaskry (Ranunculus acris, R. repens), niezapominajki (Myosotis palustris), a wiosną knieć błotną (Caltha palustris). W okresie wczesnowiosennym licznie zakwitają śnieżyczki (Galanthus nivalis), zawilce (Anemone nemorosa), ziarnopłony (Ficaria verna), fiołki (Viola reichenbachiana) i szczawiki (Oxalis acetosella). Wśród paproci często spotkać można nerecznicę samczą (Dryopteris filix-mas).

\section{METODY BADAŃ}

Badania mykologiczne w parku w Małkocinie prowadzono od maja $2008 \mathrm{r}$. do końca listopada 2009, w odstępach 2-3-tygodniowych. O długości przerw między obserwacjami decydowały warunki pogodowe. W okresach suchych wydłużały się do 3-4 tygodni, natomiast jesienią (wrzesień, październik) skracały do 1-2 tygodni. Badania nie były prowadzone w miesiącach zimowych (styczeń, luty) z powodu niskich temperatur i zalegającej pokrywy śnieżnej. Łącznie wykonano 35 obserwacji mykologicznych.

$\mathrm{Na}$ terenie parku w celu dokładniejszego określenia miejsc występowania poszczególnych gatunków grzybów wyznaczono 12 sekcji (ryc. 1). Podziału 


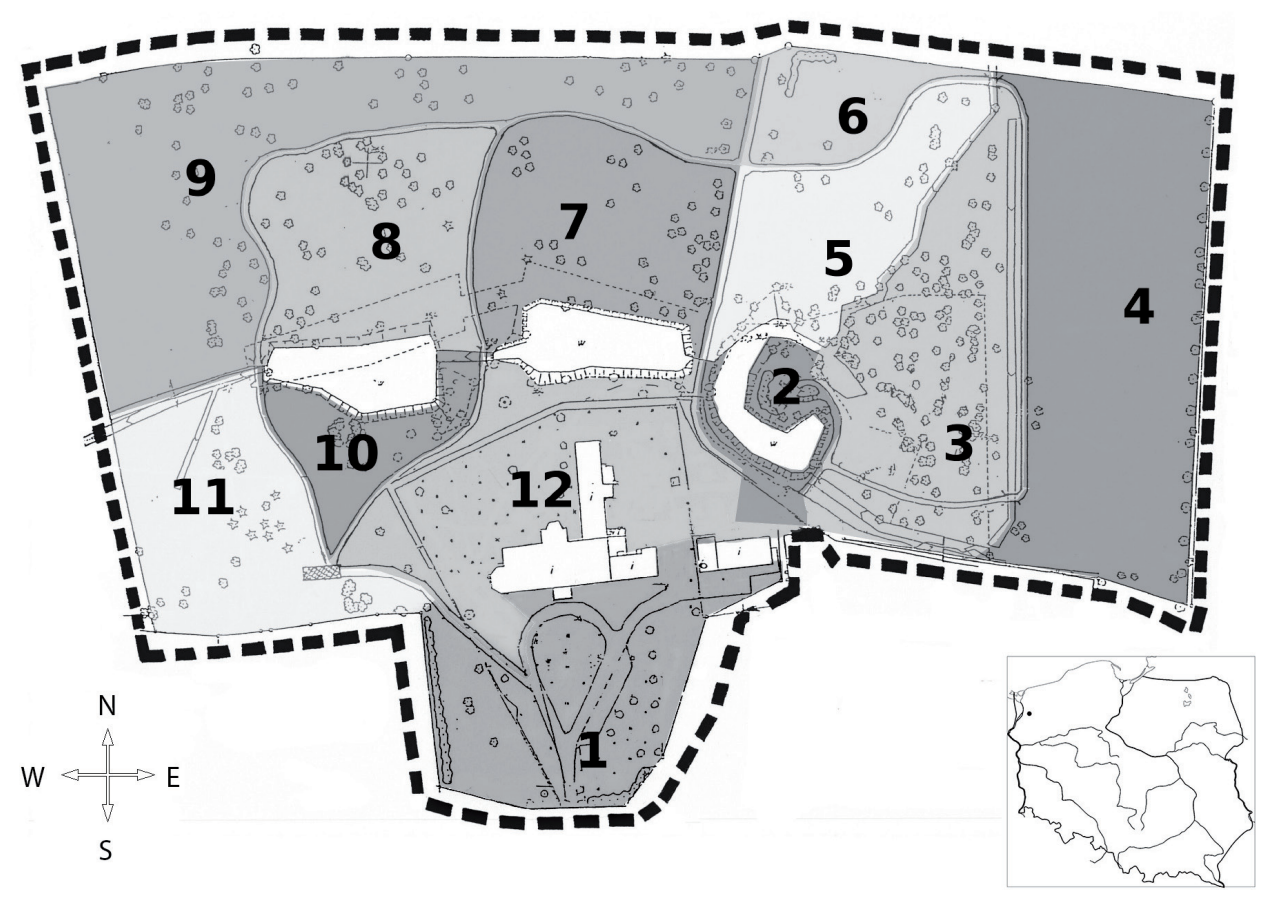

Ryc. 1. Plan parku w Małkocinie z podziałem na sekcje (Kowalczyk 2006, zmienione) 1-12 - numery sekcji; skala $1: 1000$

Fig. 1. Plan of the Małkocin park divided into sections (Kowalczyk 2006, modified) 1-12-section numbers; scale $1: 1000$

dokonano wzdłuż alejek i cieków wodnych. Poszczególne sekcje różnią się między sobą m.in. wielkością powierzchni, składem gatunkowym roślin, ilością zalegającego drewna, długością okresowych podtopień czy częstością wykonywania prac pielęgnacyjnych.

W każdej sekcji notowano liczbę owocników lub podkładek poszczególnych gatunkow grzybów oraz rodzaj podłoża, na którym występowały. Obfitość występowania podano według zmodyfikowanej trzystopniowej skali Jahna i in. (1967). Podział na grupy bioekologiczne przyjęto za Lisiewską (2000).

Dane meteorologiczne zamieszczone $\mathrm{w}$ pracy pochodzą $\mathrm{z}$ automatycznej stacji meteorologicznej Vaisala - Helsinki, oddalonej o około $36 \mathrm{~km}$ od parku w Małkocinie.

Nazewnictwo grzybów przyjęto za Index Fungorum (http://www.indexfungorum.org). Nazwy roślin naczyniowych podano za Mirkiem i in. (2002). Kategorie zagrożenia grzybów podano za Wojewodą i Ławrynowicz (2006).

Zebrany i oznaczony materiał złożono w zielniku Katedry Botaniki i Ochrony Przyrody Uniwersytetu Szczecińskiego (SZUB). 


\section{WYNIKI}

Na terenie parku Zespołu Pałacowo-Parkowego w Małkocinie stwierdzono 200 gatunków grzybów wielkoowocnikowych, w tym 172 należą do Basidiomycota i 28 do Ascomycota, ponadto cztery gatunki z Myxomycota. W odniesieniu do głównych grup bioekologicznych stwierdzono 157 gatunków saprotroficznych (77\% ogólnej liczby odnotowanych taksonów), w tym: 77 (38\%) saprotrofów nadrewnowych, 55 (27\%) saprotrofów napróchniczych i 25 (12\%) saprotrofów naściółkowych, oraz 34 (17\%) gatunki mykoryzowe i 13 (6\%) gatunków pasożytniczych.

Grzyby porastające kłody, pniaki czy gałęzie nie tylko stanowią największą liczbę gatunków, ale także występują bardzo obficie w wielu miejscach i sekcjach. Wśród nich dominują gatunki o szerokiej skali ekologicznej, zasiedlające różne typy drewna, zarówno gatunków drzew liściastych, jak i iglastych. Do najczęściej i najliczniej występujących saprotrofów nadrewnowych parku należą: Bjerkandera adusta, Coprinellus disseminatus, Mycena galericulata, Trametes hirsuta, T. versicolor i Xylaria hypoxylon. Niektóre gatunki, jak Coprinellus micaceus, Exidia glandulosa, E. nigricans, Hypoxylon fragiforme, Kretzschmaria deusta i Stereum hirsutum, upodobały sobie jako podłoże bytowania drewniane lawki, a Auricularia auricula-judae i Coprinellus domesticus drewniane mostki. U podstawy pni Pseudotsuga menziesii, Quercus robur, Fagus sylvatica i Alnus glutinosa znaleziono owocniki Hypholoma fasciculare, natomiast Coprinellus disseminatus występował przy pniach i pniakach, m.in. Aesculus hippocastanum i Populus $\times$ berolinensis. Gatunków grzybów przywiązanych do jednego rodzaju substratu stwierdzono tylko kilka. Na gałązkach Quercus sp. znaleziono Colpoma quercinum, Diatrypella quercina i Peniophora quercina.

Drugą co do wielkości grupę troficzną parku stanowią saprotrofy napróchnicze. Grzyby te rosły głównie wśród traw, na ziemi. Do najczęściej i najliczniej spotykanych należały: Coprinopsis atramentaria, Coprinus comatus, Gymnopus dryophilus, Lepiota cristata, Melanoleuca melaleuca, Parasola conopilus i Stropharia aeruginosa.

Wśród saprotrofów naściółkowych najczęściej notowanymi gatunkami były: Hymenoscyphus herbarus, Mycena filopes, M. vitilis, M. zephirus i Tubaria furfuracea. Na opadłych szyszkach Pseudotsuga i Picea występowały $B a-$ eospora myosura i Strobilurus esculentus. Miseczki Fagus były odpowiednim substratem dla Ciboria batschiana i Xylaria carpophila, owoce Quercus dla Hymenoscyphus fructigenes, a ogonki liści Acer dla Lanzia luteovirescens. Na podkładkach Diatrype stigma i Diatrypella quercina występowała Dialonectria episphaeria.

Grzyby mykoryzowe, żyjące $\mathrm{w}$ mutualistycznej symbiozie z roślinami naczyniowymi, nie stanowią w parku dużej grupy gatunków (34). Są to głównie grzyby tworzące mykoryzę z drzewami z rodzaju Quercus (17 gatunków), 
Fagus (7), Carpinus (6) i Alnus (3). Pod drzewami iglastymi odnotowano tylko pięć gatunków grzybów mykoryzowych. Należy podkreślić, że pod starymi okazami drzew rósł więcej niż jeden gatunek mykoryzowy, np. pod Betula pendula znaleziono dwa (Amanita rubescens, Russula betularum), a pod Quercus robur - pomnikiem przyrody - cztery (Amanita phalloides, Boletus subtomentosus, Inocybe geophylla i Scleroderma verrucosum).

Najmniej liczną grupę stanowią pasożyty (13 gatunków), w której dominują taksony o szerokiej skali ekologicznej, atakujące różne gatunki drzew. Do najczęściej spotykanych na terenie parku należały: Armillaria ostoyae, Flammulina velutipes, Nectria cinnabarina i Pholiota squarrosa. Gatunki grzybów wytwarzające trwałe i wieloletnie owocniki, jak Fomes fomentarius, Fomitopsis pinicola, Fuscoporia ferruginosa i Phellinus igniarius, występowały rzadko. Najczęściej atakowanymi drzewami były dęby i wierzby. Spośród odnotowanych gatunków tylko dwa nie były pasożytami drzew: Rickenella fibula (pasożytuje na mchach) i Tremella mesenterica (pasożytuje na grzybach z rodziny Corticiaceae).

Największym bogactwem gatunkowym grzybów wielkoowocnikowych charakteryzowała się sekcja 9 (82 gatunki), a najmniej gatunków (tylko 16) zanotowano w sekcji 5. O liczbie gatunków w poszczególnych sekcjach decydowały głównie warunki siedliskowe. W sekcjach z największą liczbą gatunków (sekcje 9,6,11) zalegały duże ilości zmurszałego drewna, rosło wiele różnych gatunków drzew, w tym bardzo stare egzemplarze, a runo nie był zwarte. Sekcje z najmniejszą liczbą gatunków (sekcje 5 i 4) to tereny z niewielką liczbą drzew, porośnięte przez cały okres wegetacji zwartą roślinnością zielną (głównie Urtica dioica i Aegopodium podagraria).

W każdej z sekcji, z wyjątkiem sekcji 1, gdzie dominowały saprotrofy napróchnicze, najliczniejszą grupę grzybów stanowiły saprotrofy nadrewnowe. W sekcji 2 nie zanotowano ani jednego przedstawiciela saprotrofów naściółkowych, a w sekcjach 4 i 5 żadnego gatunku mykoryzowego. Najczęściej występującym w parku gatunkiem była Bjerkandera adusta, którą notowano w dziewięciu sekcjach. W ośmiu sekcjach rosły Mycena vitilis i Xylaria hypoxylon, w siedmiu Armillaria ostoyae, Coprinellus disseminatus, Mycena galericulata, Stropharia aeruginosa, Tubaria furfuracea i Nectria cinnabarina.

$\mathrm{Na}$ czerwonej liście grzybów wielkoowocnikowych Polski (Wojewoda, Ławrynowicz 2006) znajduje się 11 taksonów notowanych w parku. Do kategorii wymierających (E) należy Geastrum triplex, do narażonych (V) Rhizomarasmius setosus, do rzadkich (R): Amanita strobiliformis, Entoloma chalybaeum, Lentinus tigrinus, Mycena croccata, Polyporus tuberaster, Russula amoenolens i Typhula fistulosa, a do kategorii o nieokreślonym zagrożeniu (I): Coltricia cinnamomea i Pluteus plautus. Na terenie parku nie stwierdzono grzybów podlegających ochronie (Rozporządzenie... 2014). 


\section{WYKAZ GATUNKÓW}

Przyjęte skróty: sek. - sekcja; V-X 2008 - miesiąc/miesiące i rok; obfitość występowania: $\mathrm{r}$ (rarus) - gatunek występujący pojedynczo lub w niewielu egzemplarzach, w jednym miejscu; $\mathrm{n}$ (numerous) - gatunek występujący niezbyt licznie, rozproszony w sekcjach, pojedynczo lub po kilka, a (abundans) - gatunek występujący w dużej liczbie egzemplarzy, w wielu miejscach, w wielu sekcjach; grupy bioekologiczne: $\mathrm{M}$ - grzyby mykoryzowe, $\mathrm{Sw}$ - grzyby saprotroficzne nadrewnowe, S1 - grzyby saprotroficzne naściółkowe, Sh - grzyby saprotroficzne napróchniczne, $\mathrm{P}$ - grzyby pasożytnicze; kategorie zagrożenia: $\mathrm{E}$ - wymierające, $\mathrm{V}$ - narażone, $\mathrm{R}$ - rzadkie, I o nieokreślonym zagrożeniu.

\section{Myxomycota}

Ceratiomyxa fruticulosa (O.F. Müll.) T. Macbr. - S1, na łodygach roślin zielnych; r; VII 2008; sek.: 6 .

Fuligo septica (L.) F.H. Wigg. - Sw, na pniaku; r; VII 2009; sek.: 7.

Lycogala epidendrum (J.C. Buxb. ex L.) Fr. - Sw, na kłodzie; r; V 2008, IV 2009; sek.: 9.

Stemonitis sp. - Sw, na gałązce; r; IX 2009; sek.: 8.

\section{Ascomycota}

Anthracobia cf. maurilabra (Cooke) Boud. - Sh, na wypalenisku; r; VII 2008; sek.: 9.

Ascocoryne sarcoides (Jacq.) J.W. Groves \& D.E. Wilson [=Coryne sarcoides (Jacq.) Tul.] Sw, kłody i pniaki; n; X 2008, XI 2009; sek.: 1, 6, 11.

Cheilymenia vitellina (Pers.) Dennis [=Lachnea vitellina (Pers.: Fr.) Phillips] - Sh, na ziemi; r; IX 2009; sek.: 12.

Ciboria batschiana (Zopf) N.F. Buchw. - Sl, na miseczkach Fagus; r; IX 2008; sek.: 8.

Colpoma quercinum (Pers.) Wallr. - Sw, na gałązkach Quercus; n; V 2008; sek.: 9, 12.

Dialonectria episphaeria (Tode) Cooke [=Nectria episphaeria (Tode ex Fr.) Fr.] - S1, na Diatrype stigma i Diatrypella quercina; n; V 2008, IX 2009; sek.: 6, 9.

Diatrype disciformis (Hoffm.) Fr. - Sw, na gałęziach; n; VIII 2008; sek.: 8, 10.

D. stigma (Hoffm.) Fr. - Sw, na gałęziach; n; V-VI 2008; sek.: 6, 10.

Diatrypella quercina (Pers.) Cooke. - Sw, na gałązkach Quercus; r; VI 2008, IX 2009; sek.: 9.

Helvella crispa (Scop.) Fr. - Sh, na ziemi; n; X, XII 2008; sek.: 2, 7.

Hymenoscyphus fructigenus (Bull.) Gray - S1, na owocach Quercus; n; VIII 2008, IX, X 2009; sek.: $8,9$.

H. herbarum (Pers.) Dennis - Sl, na łodygach roślin zielnych; a; VII 2008-2009, VIII 2008, X 2009; sek.: 1, 4, 7, 9, 10, 11.

Hypoxylon fragiforme (Pers.) J. Kickx f. - Sw, na gałęziach, drewnianych ławkach; n; V-VIII 2008; III 2009; sek.: 2, 5, 8, 9, 12.

Hysterium cf. pulicare Pers. - Sw, na kłodzie; r; X 2008; sek.: 6.

Kretzschmaria deusta (Hoffm.) P.M.D. Martin [=Ustulina deusta (Fr.) Petrak] - Sw, na kłodach, pniakach, drewnianych ławkach; n; V-VI 2008-2009, XI 2008, VI, IX 2009; sek.: 1, 2, 6, 8.

Lanzia luteovirescens (Roberge ex Desm.) Dumont \& Korf - Sl, na ogonkach liści Acer; r; X 2009; sek.: 11.

Nectria cinnabarina (Tode) Fr. - P, na gałązkach, gałęziach, łodygach Rosa i roślin zielnych; a; X-XII 2008-2009, III 2009, V 2008; sek.: 2, 5, 6, 8, 9, 10, 11.

Peziza michelii (Boud.) Dennis - Sh, na ziemi; r; VI 2009; sek.: 12.

P. micropus Pers. - Sw, na kłodzie; r; X-XII 2008; sek.: 6.

P. vesiculosa Bull. - Sh, na ziemi; r; V 2008; sek.: 9. 
Pyronema omphalodes (Bull.) Fuckel - Sh, na wypalenisku; r; VIII 2009; sek.: 9.

Scutellinia scutellata (L.) Lambotte - Sh, na ziemi, pod gałęziami; r; IX 2008; sek.: 3.

Sphaerosporella brunnea (Alb. \& Schwein.) Svrček \& Kubička - Sh, na wypalenisku; r; VII 2009; sek.: 9.

Tarzetta cupularis (L.) Svrček - sh, na ziemi; r; VI 2009; sek.: 11.

Valsa nivea (Hoffm.) Fr. [=Leucostoma niveum (Pers. ex Fr.) von Höhnel] - Sw, na gałązkach; r; VIII 2008; sek.: 3.

Xylaria carpophila (Pers.) Fr. - Sl, na miseczkach Fagus; r; V 2008; sek.: 7.

X. hypoxylon (L.) Grev. - Sw, na kłodach, pniakach; a; X-XII 2008, III-IV 2009; sek.: 1, 2, 3, 4, $6,8,9,12$.

X. polymorpha (Pers.) Grev. - Sw, na kłodach, pniakach; n; VIII 2008, VI-VII, XI 2009; sek.: 5.

\section{Basidiomycota}

Agaricus bitorquis (Quél.) Sacc. - Sh, na ziemi, pod Fagus; r; VIII, IX 2008, VI 2009; sek.: 7.

Agrocybe dura (Bolton) Singer - Sh, trawnik; r; VIII 2008, V, IX 2009; sek.: 2.

A. pediades (Fr.) Fayod - Sh, w trawie; n; V-VI 2009; sek.: 1, 7.

A. praecox (Pers.) Fayod - Sh, na ziemi; n; V-VI 2008-2009; sek.: 6, 12.

Amanita phalloides (Vaill. ex Fr.) Link - M, na ziemi, pod Quercus; r; VII 2009; sek.: 12.

A. rubescens Pers. - M, na ziemi, pod Betula; r; VII, IX 2008, VIII 2009; sek.: 8.

A. strobiliformis (Paulet ex Vittad.) Bertillon - M, na ziemi, pod Carpinus; r; IX 2008; sek.: 2, R (Kwiatkowska 2015).

Armillaria ostoyae (Romagn.) Herink - P, u podstawy pni drzew, na leżących kłodach, na ziemi; a; X, XI 2008-2009; sek.: 1, 2, 5, 8, 9, 10, 11.

Auricularia auricula-judae (Bull.) Quél. - Sw, na gałęziach, kłodach, pniakach, drewnianych mostkach; n; X-XII 2008, XI 2009; sek.: 3, 4, 10, 11, 12.

Baeospora myosura (Fr.) Singer - Sl, na szyszkach Pseudotsuga i Picea zagrzebanych w ziemi; n; IX 2008, X 2009; sek.: 8, 10.

Bjerkandera adusta (Willd.) P. Karst. - Sw, na pniakach, kłodach, ławkach; a; 2008, 2009; sek.: $1,2,3,4,6,7,8,9,12$.

Boletus subtomentosus L. [=Xerocomus subtomentosus (L.: Fr.) Quél. var. subtomentosus] M, na ziemi, pod Quercus; r; VII 2009; sek.: 12.

Calvatia gigantea (Batsch) Lloyd [=Langermannia gigantea (Batsch: Pers.) Rostk.] - Sh, na ziemi; r; IX 2008; sek.: 11.

Cerioporus mollis (Sommerf.) Zmitr. \& Kovalenko [=Datronia mollis (Sommerf.: Fr.) Donk] - Sw, na kłodach; n; V, IX-XII 2008, III, V 2009; sek.: 6, 8, 9.

C. squamosus (Huds.) Quél. [=Polyporus squamosus (Huds.) Fr.] - Sw, na kłodach; n; VII-VIII 2008, VII, IX 2009; sek.: 2, 4, 6.

C. varius (Pers.) Zmitr. \& Kovalenko [=Polyporus varius (Pers.): Fr.] - Sw, na gałązce pod Fagus; VI 2009; r; sek.: 7.

Connopus acervatus (Fr.) K.W. Hughes, Mather \& R.H. Petersen [=Gymnopus acervatus (Fr.) Murrill] - Sh, na korzeniach Quercus; r; XII 2009; sek.: 4.

Chlorophyllum rachodes (Vittad.) Vellinga [=Macrolepiota rhacodes ('rachodes') (Vittad.) Singer var. rhacodes] - Sh, na ziemi; r; XI 2009; sek.: 3.

Chondrostereum purpureum (Schum.) Pouzar - P, na pniakach i gałęziach; X-XII 2008-2009; n, sek.: 2, 3, 6, 11 .

Coltricia cinnamomea (Jacq.) Murrill - Sh, na wypalenisku; r; VII, IX 2009; sek.: 9, I.

Conocybe apala (Fr.) Arnolds [=C. albipes (Otth) Hauskn., C. lactea (J.E. Lange) Métrod] Sh, w trawie; r; VI 2009; sek.: 6.

C. arrhenii (Fr.) Kits van Wav. [=Pholiotina arrhenii (Fr.) Singer] - Sh, na ziemi; n; X 20082009; sek.: 7, 11, 12. 
C. cf. fuscimarginata (Murrill) Singer [=? C. rickenii (J. Schäff.) Kühn.] - Sh, na ziemi; r; VI 2009; sek.: 7.

C. rickeniana P.D. Orton - Sh, na ziemi; n; IX 2008, VII, X 2009; sek.: 3, 7, 8.

C. cf. subpubescens P.D. Orton [=C. cryptocystis (Atk.) Singer \& M.M. Moser] - Sh, na ziemi; n; IX 2008; sek.: 1, 2, 9.

Coprinellus angulatus (Peck) Redhead, Vilgalys \& Moncalvo [=Coprinus angulatus Peck non J.K. Lange., C. boudieri Quél.] - Sh, na wypalenisku; r; XI, X 2009; sek.: 9.

C. disseminatus (Pers.) J.E. Lange [=Coprinus disseminatus (Pers.: Fr.) Quél.] - Sw, na ziemi, na pniakach, pod drzewami; a; VIII-X 2008-2009; sek.: 1, 2, 3, 4, 6, 8, 9.

C. domesticus (Bolton) Vilgalys, Hopple \& Jacq. Johnson [=Coprinus domesticus (Bolt.: Fr.) Gray] - Sw, na pniakach, drewnianych mostkach; n; V, VIII, IX 2008, VI 2009; sek.: 1, 3, 4, 6.

C. micaceus (Bull.) Vilgalys, Hopple \& Jacq. Johnson [=Coprinus micaceus (Bull.: Fr.) Fr.] - Sw, na drewnie i na ziemi, przy podstwie pni Fagus i Quercus, przy drewnianej ławce; a; VI-XI 2008-2009; sek.: 4, 7, 9, 10, 12.

C. xanthothrix (Romagn.) Vilgalys, Hopple \& Jacq. Johnson [=Coprinus xanthothrix Romagn.] - Sl, na gałązkach, drewnie, miseczkach Fagus; n; VIII-X 2008, IV 2009; sek.: 3, 6, 8, 11.

Coprinopsis atramentaria (Bull.) Redhead, Vilgalys \& Moncalvo [=Coprinus atramentarius (Bull.: Fr.) Fr. var. atramentarius] - Sh, w trawie; a; VIII-XII 2008-2009; sek.: 1, 3, 6, 9, $11,12$.

C. cf. lagopides (P. Karst.) Redhead, Vilgalys \& Moncalvo [=Coprinus lagopides P. Karst., C. lagopus var. sphaerospora Kühn. \& Joss.] - Sh, na ziemi; r; XI 2008; sek.: 3.

Coprinus comatus (O.F. Müll.) Pers. - Sh, w trawie; a; IX-XI 2008-2009; sek.: 1, 7, 10, 12.

Crepidotus cesatii (Rabenh.) Sacc. - Sw, na gałązkach; r; XI 2009; sek.: 6.

C. mollis (Schaeff.) Staude - Sw, na kłodzie; r; X 2008; sek.: 6.

Crucibulum laeve (Huds.) Kambly - Sw, na gałązkach; n; IX-X 2008-2009, IV 2009; sek.: 7, 11. Cyathus striatus (Huds.) Willd. - Sh, na ziemi; r; VIII 2008; sek.: 1.

Dacrymyces stillatus Nees - Sw, na gałęzi; r; VI 2008; sek.: 9.

Daedalea quercina (L.) Pers. - P, na pniakach, kłodach Quercus, drewnianych ławkach; n; VI, VIII-IX, XII 2008, X 2009; sek.: 1, 3, 6, 8.

Daedaleopsis confragosa (Bolton.) J. Schröt. - Sw, na kłodach i gałęziach pod Alnus i Carpinus; n; VIII-X, XII 2008; sek.: 2, 3.

Echinoderma asperum (Pers.) Bon [=Lepiota aspera (Pers.: Fr.) Quél.] - Sh, na ziemi; n; X 2009; sek.: 8, 10.

Entoloma chalybeum (Pers.) Noordel - Sh, w trawie; r; IX 2008; sek.: 4, R.

E. rhodopolium (Fr.) P. Kumm. - Sh, w trawie, na ziemi; n; IX, XI 2008; sek.: 3, 4, 12.

E. sericeum Quél. - Sh, na ziemi; r; VIII 2008; sek.: 8 .

Exidia glandulosa (Bull.) Fr. [=E. truncata Fr. ss. auct.] - Sw, na gałęziach, ławkach; n; XI, XII 2008, III 2009; sek.: 8, 9, 11.

E. nigricans (With.) P. Roberts [=E. plana (Wiggers) Donk] - Sw, na gałęziach, kłodach, ławkach; a; V, VI, X-XII 2008-2009; sek.: 3, 5, 6, 11, 12.

Flammulina velutipes (Curtis) Singer - P, na pniakach, kłodach i pniach m.in. Salix, Quercus, Fagus; a; X-XII 2008, III 2009; sek.: 2, 3, 4, 6, 11.

Fomes fomentarius (L.) Gillet - P, na pniu i kłodzie; n; VIII 2008; sek.: 3, 8.

Fomitopsis pinicola (Sw.) P. Karst. - P, na pniu Salix; r; IV 2009; sek.: 3.

Fuscoporia ferruginosa (Schrad.) Murrill [=Phellinus ferruginosus (Schrad.: Fr.) Pat.] - P, na gałęzi; r; V 2008; sek.: 9.

Ganoderma applanatum (Pers.) Pat. - Sw, na pniaku; r; IV 2009; sek.: 10.

Geastrum triplex Jungh. - M, na ziemi pod Fraxinus, Quercus; n; III, IX-X 2009; sek.: 7, 9, E.

Gymnopus confluens (Pers.) Antoín, Halling \& Noordel. - Sl, wśród igieł, pod Picea i Pseudotsuga; $\mathrm{r}$; X 2008; sek.: 11.

G. dryophilus (Bull.) Murrill - Sh, na ziemi; a; VIII-XI 2008, VII, X 2009; sek.: 1, 7, 8, 11, 12. 
G. erythropus (Pers.) Antoín, Halling \& Noordel. - Sw, na gałązkach, pod Fagus, Carpinus; n; IX 2008, X 2008-2009; sek.: 7, 11.

G. peronatus (Bolton) Gray - Sl, na ziemi, wśród liści i igieł; n; VIII-X 2008, X-XI 2009; sek.: $9,11$.

Hapalopilus nidulans (Fr.) P. Karst. - Sw, na kłodzie; r; IX 2008; sek.: 3.

Hebeloma anthracophilum Maire - M, na ziemi; r; IX 2008; sek.: 8.

H. crustuliniforme (Bull.) Quél. - M, pod Quercus; n; X 2009; sek.: 6, 9.

H. cf. populinum Romagn. [=H. xerophilum Rudnicka-Jezierska p.p.] - M, na ziemi; r; X 2008; sek.: 12.

Hohenbuehelia atrocoerulea (Fr.) Singer - Sw, na kłodzie; r; IX 2009; sek.: 3.

Hymenopellis radicata (Relhan) R.H. Petersen [=Xerula radicata (Relh.: Fr) Dörfelt] - Sw, na kłodach; n; IX-X 2008-2009, VII 2009; sek.: 7, 8, 9, 10.

Hypholoma capnoides (Fr.) P. Kumm. - Sw, na kłodzie; r; X 2008; sek.: 9.

H. fasciculare (Huds.) P. Kumm. - Sw, u podstawy pni Pseudotsuga, Quercus, Fagus, na pniu Alnus; n; IX-X 2008; sek.: 3, 8, 9, 11.

H. lateritium (Schaeff.) P. Kumm. - Sw, na kłodzie; r; XI 2008; sek.: 9.

Inocybe cookei Bres. - M, na ziemi, pod Alnus, Quercus, Fagus; n; VIII-X 2008; sek.: 2, 3, 8, 9.

I. geophylla (Bull.) P. Kumm. var. geophylla - M, na ziemi, pod Quercus; n; IX, X 2008-2009; sek.: 9, 11.

I. geophylla (Bull.) P. Kumm. var. lilacina - M, na ziemi, pod Quercus, Carpinus; n; IX 2008, X 2009; sek.: 8, 9, 10, 12.

I. perlata (Cooke) Sacc. - M, na ziemi, pod Quercus; r; IX 2009; sek.: 10.

I. praetervisa Quél. - M, na ziemi, pod Abies, Quercus; n; IX-X 2008, VI 2009; sek.: 11, 12.

I. phaeoleuca Kühn. [=I. splendens Heim var. phaeoleuca (Kühn.) Kuyper] - M, na ziemi, pod Tilia, Alnus; n; VI, X 2009; sek.: 2, 12.

Laccaria laccata (Scop.) Cooke - M, na ziemi, we mchu, m.in. pod Fagus, Quercus; n; X 20082009; sek.: 8, 9, 11.

Lacrymaria lacrymabunda (Bull.) Pat. [=Psathyrella lacrymabunda (Bull.: Fr.) M.M. Moser] - Sh, na ziemi, pod Quercus; r; X 2009; sek.: 6.

Lactarius fluens Boud. - M, na ziemi, pod Carpinus, Quercus i Fagus; n; IX-X 2008-2009, IV 2009; sek.: 8, 9, 10.

L. cf. omphaliiformis Romagn. [=L. tabidus Fr. ss. Neuhoff] - M, na ziemi; n; X 2009; sek.: 9, 11.

L. rufus (Scop.) Fr. - M, na ziemi, w pobliżu Picea; r; IX 2008; sek.: 9.

L. subdulcis (Pers.) Gray - M, na ziemi, pod Fagus; r; XI 2008-2009; sek.: 9.

Laetiporus sulphureus (Bull.) Murrill - P, na pniu Quercus; r; IX 2009; sek.: 9.

Lentinus brumalis (Pers.) Zmitr. [=Polyporus brumalis (Pers.): Fr.] - Sw, na gałęziach, gałązkach; n; XII 2008, IV 2009; sek.: 4, 5, 10, 11, 12.

L. substrictus (Bolton) Zmitr. \& Kovalenko [=P. ciliatus Fr.: Fr., P. lepideus Fr.] - Sw, na pniaku po Fraxinus; r; IV-VI 2009; sek.: 6.

L. tigrinus (Bull.) Fr. [=Panus tigrinus (Bull.: Fr.) Singer] - Sw, na pniaku po Fraxinus; r; IV 2009; sek.: 6, R.

Lepiota cristata (Bolton) P. Kumm. - Sh, w trawie; a; VIII-XI 2008, VII, IX-XI 2009; sek.: 1, $3,6,7,8,11$.

Lepista nuda (Bull.) Cooke - Sh, na ziemi, liściach; n; X, XII 2008, X-XI 2009; sek.: 2, 11.

Lycoperdon excipuliforme (Scop.) Pers. [=Calvatia excipuliformis (Scop.: Pers.) Perdeck] Sh, na ścieżce; r; IX 2008; sek.: 8.

L. molle Pers. - Sh, na ziemi, na ścieżce; r; VIII-IX 2008; sek.: 7.

L. pyriforme Schaeff. - Sw, na pniach Quercus i Fagus; n; VIII-XII 2008-2009, V 2008, IV 2009; sek.: 7, 8, 9, 12 .

Macrocystidia cucumis (Pers.) Joss. - Sl, wśród liści Aesculus, szyszek i igieł Picea; r; XI 2009; sek.: 7. 
Marasmius cohaerens (Pers.) Cooke \& Quél. - Sl, wśród liści Fagus, Quercus; n; IX 2008, X 2009; sek.: 7, 8, 9.

M. rotula (Scop.) Fr. - Sw, na gałązkach; n; VIII 2008, IX 2009; sek.: 3, 4, 9.

Megacollybia platyphylla (Pers.) Kotl. \& Pouzar - Sw, na kłodach; n; IV, VIII, IX 2008, V, VII 2009; sek.: 3, 5, 8, 9.

Melanoleuca melaleuca (Per.: Fr.) Murrill - Sh, na ziemi; a; X-XI 2008-2009; sek.: 1, 3, 6, 7, $9,11$.

Mensularia nodulosa (Fr.) T. Wagner \& M. Fisch. [=Inonotus nodulosus (Fr.) P. Karst.] - Sw, na kłodzie; XII 2008; r; sek.: 6.

Meripilus giganteus (Pers.) P. Karst - Sw, na pniu Fagus; r; VIII 2008-2009; sek.: 8.

Mycena acicula (Schaeff.) P. Kumm. - Sl, na ziemi; n; VII 2008, IX 2009; sek.: 6, 9, 10.

M. crocata (Schrad.) P. Kumm. - S1, na gałązce; r; IX 2008; sek.: 9, R.

M. filopes (Bull.) P. Kumm. - Sl, na drobnych gałązkach; XI-XII 2008, IX, XI 2009; a; sek.: 4, $5,9,10,11,12$.

M. galericulata (Scop.) Gray - Sw, gałęzie, pniaki, kłody; a; VIII-XI 2008-2009; sek.: 1, 3, 4, $5,7,9,11$.

M. galopus (Pers.) P. Kumm. - S1, na ziemi, wśród liści; n; XI 2008, IX-XI 2009; sek.: 3, 9.

M. haematopus (Pers.) P. Kumm. - Sw, na porośniętych mchem pniakach Quercus, Fagus; n; VI, XI 2009; sek.: 7, 9.

M. polygramma (Bull.) Gray - Sw, na gałęziach, wśród mchów; a; IX-XII 2008, X-XI 2009; sek.: $3,7,8,9,12$.

M. sanguinolenta (Alb. \& Schwein.) P. Kumm. - Sl, na szyszkach; n; VII, X 2008; sek.: 6, 11.

M. tintinnabulum (Paulet) Quél. - Sw, na kłodzie i pniaku; n; XI 2008-2009; sek.: 5, 9.

M. vitilis (Fr.) Quél. - Sl, na drobnych gałązkach; a; XII 2008, X-XI 2009; sek.: 3, 4, 5, 7, 8, 9 , $10,12$.

M. vulgaris (Pers.) P. Kumm. - Sh, na ziemi i ściółce iglastej; r; XI 2009; sek.: 11.

M. zephirus (Fr.) P. Kumm. - Sl, na ściółce; a; X-XII 2008, X-XI 2009; sek.: 8-12.

Mycetinis querceus (Britzelm.) Antonín \& Noordel. [=Marasmius querceus Britzelm.] - S1, na liściach Quercus; r; XI-XII 2008; sek.: 9.

Omphalina pyxidata (Bull.) Quél. - Sh, na ziemi wśród mchów, na ścieżce; n; VIII, X 2008, IV, VI, X, XI 2009; sek.: 4, 6.

Panellus serotinus (Pers.) Kühn. - Sw, na kłodach; n; X-XI 2008; sek.: 3, 6.

Parasola auricoma (Pat.) Redhead, Vilgalys \& Hopple [=Coprinus auricomus Pat.] - Sh, w trawie; n; VI, IX 2009; sek.: 2, 6.

P. conopilus (Fr.) Örstadius \& E. Larss. [=Psathyrella conopilus ('conopila, conopilea') (Fr.: Fr.) A. Pearson \& Dennis] - Sh, na ziemi; n; VIII, X 2008, XI 2008-2009; sek.: 3, 6, 7, 10, 11.

P. hemerobia (Fr.) Redhead, Vilgalys \& Hopple [=Coprinus hemerobius Fr. ss. J.E. Lange] Sh, w trawie; n; XI 2008-2009; sek.: 4, 11.

P. plicatilis (Curtis) Redhead, Vilgalys \& Hopple [=Coprinus plicatilis (M.A. Curtis: Fr.) Fr.] - Sh, w trawie, n; VII, X 2008, VI, IX 2009; sek.: 1, 6, 10, 12.

Paxillus involutus (Batsch) Fr. - M, na ziemi, pod Quercus, Alnus; n; VIII-X 2008, IX 2009; sek.: 2, 6, 10, 11.

Peniophora cinerea (Pers.) Cooke - Sw, na gałęziach; n; VI, VIII 2008; sek.: 1, 7.

P. incarnata (Pers.) P. Karst. - Sw, na gałęziach; n; V, XI 2008, III 2009; sek.: 3, 6, 9.

P. quercina (Pers.) Cooke - Sw, na gałęziach Quercus; n; V, VI, IX 2008, IV, V 2009; sek.: 4, 8, $9,11,12$.

Phallus impudicus L. - M, na ziemi, w trawie; r; VI-VII 2009; sek.: 2.

Phellinus igniarius (L.) Quél. - P, na pniu Salix; r; V 2009; sek.: 3.

Phlebia radiata Fr. - Sw, kłody, gałęzie; n; XI-XII 2008; sek.: 2, 11.

Phloeomana hiemalis (Osbeck) Redhead [=Mycena hiemalis (Osbeck: Fr.) Quél.] - Sl, na porośniętych mchem kłodach; n; X 2008, XI 2009; sek.: 6, 9. 
Pholiota highlandensis (Peck) Quadr. \& Lunghini [=P. carbonaria (Fr.: Fr.) Singer] - Sh, na wypalenisku; r; VIII 2009; sek.: 9.

P. squarrosa (Vahl) P. Kumm. - P, u podstawy pni Fraxinus, Quercus, Fagus, Pseudotsuga; n; IX 2008; IX-X 2009; sek.: 4, 7, 9, 11.

Pleurotus ostreatus (Jacq.) P. Kumm. - Sw, na kłodach; r; XII 2008, XI 2009; sek.: 6.

Pluteus cervinus (Schaeff.) P. Kumm. - Sw, na kłodach; n; VI, VIII-X 2008, X-XI 2009; sek.: $3,7,8$.

P. cinereofuscus J.E. Lange - Sw, na drewnie zagrzebanym w ziemi, pod Fagus; n; VIII-IX 2008; sek.: $1,8$.

P. nanus (Pers.) P. Kumm. - Sw, na gałązkach, na wypalenisku; n; IV, VI, VII, IX 2009; sek.: 6, 7,9 .

P. plautus (Weinm.) Gillet - Sw, na gałęzi pod Fagus; r; IX 2009; sek.: 8, I.

P. salicinus (Pers.) P. Kumm. - Sw, na pniu, kłodzie; n; IX 2008; VI 2009; sek.: 2, 9.

P. umbrosus (Pers.) P. Kumm. - Sw, pod Quercus; r; VI 2009; sek.: 6.

Polyporus tuberaster (Jacq. ex Pers.) Fr. - Sw, pod Alnus i Quercus; r; X 2009; sek.: 2, 11, R.

Psathyrella candolleana (Fr.) Maire - Sh, na ziemi; n; V, IX 2008, VI 2009; sek.: 4, 6, 7.

P. corrugis (Pers.) Konrad \& Maubl. [=Psathyrella gracilis (Fr.: Fr.) Quél.] - Sh, na ziemi; n; X 2008-2009, XI, XII 2008; sek.: 3, 6, 9.

P. multipedata (Peck) A.H. Sm. - Sh, na ziemi, pod Quercus; r; IX 2008; sek.: 9.

P. ochracea (Romagn.) M.M. Moser ex Kits van Wav. - Sh, na ziemi, wśród liści; n; X-XI 2008; sek.: $5,7$.

P. prona (Fr.) Gillet - Sh, na ziemi; n; X-XI 2008; sek.: 9, 11.

P. pseudogracilis (Romagn.) M.M. Moser - Sh, na ziemi; r; VI 2008; sek.: 9.

Psilocybe coronilla (Bull.) Noordel. - Sh, w trawie; n; IX-X 2009; sek.: 1.

Ramaria stricta (Pers.) Quél. - Sh, na ziemi, pod Carpinus; r; VIII 2008, IX 2008-2009; sek.: 10.

Resupinatus trichotis (Pers.) Singer - Sw, na gałęzi; r; V 2008; sek.: 9.

Rhizomarasmius setosus (Sowerby) Antonín \& A. Urb. [=Marasmius setosus (Sowerby) Noordel., M. recubans Quél.] - S1, na gałązkach, miseczkach Quercus; n; VII 2008, X 2009; sek.: $8,9,10, \mathbf{V}$.

Rhodocollybia butyracea (Bull.) Lennox - M, na ściółce pod Pseudotsuga, Picea; n; X 20082009, XI 2009; sek.: 8, 11.

Rickenella fibula (Bull.) Raithelh. - P, we mchu; n; XI 2008, X 2009; sek.: 9, 10.

Russula amoenolens Romagn. - M, na ziemi pod Quercus; r; IX 2008; sek.: 7, R.

R. betularum Hora - M, na ziemi pod Betula; r; VIII 2008; sek.: 8.

$\boldsymbol{R}$. cf. cuprea J.E. Lange [ $\boldsymbol{R}$. urens March. ('Romell' emend. March.).] - M, na ziemi pod Carpinus, Quercus; n; IX 2008, VI 2009; sek.: 8, 9.

R. foetens Pers. - M, na ziemi pod Quercus; r; IX, XI 2008, sek.: 12.

R. solaris Ferd. \& Winge - M, we mchu pod Fagus; r; IX 2009; sek.: 9.

Schizophyllum amplum (Lév.) Nakasone [=Auriculariopsis ampla (Lév.) Maire] - Sw, na gałęziach; r; III 2009; sek.: 4.

S. commune Fr. - Sw, na gałęziach, kłodach; n; V, IX, X, XII 2008, III, VI 2009; sek.: 2, 3, 6.

Schizopora paradoxa (Schrad.) Donk - Sw, na gałęziach, kłodach; n; V-VIII 2008, III 2009; sek.: $3,5,6,9,12$.

Scleroderma areolatum Ehrenb. - M, na ziemi pod Quercus; n; IX 2008, VII 2009; sek.: 1, 2, 6.

S. bovista Fr. - M, na ziemi pod Quercus; r; VIII-IX 2008; sek.: 9.

S. verrucosum (Bull.) Pers. - M, na ziemi, pod Quercus, Fagus, Carpinus; n; VIII-IX 2008, VI, IX-X 2009; sek.: 2, 8, 9, 12.

Stereum hirsutum (Willd.) Pers. - Sw, na gałęziach, kłodach, drewnianych ławkach; n; VI, IX, XI-XII 2008; sek.: 3, 6, 8, 11, 12.

S. rugosum Pers. - Sw, na kłodach, pniakach; n; V, XI-XII 2008, III 2009; sek.: 3, 4, 9.

S. sanguinolentum (Alb. \& Schwein.) Fr. - Sw, na kłodzie; r; VIII 2008; sek.: 3. 
Strobilurus esculentus (Wulfen) Singer - Sl, na szyszkach; n; IV, X-XI 2009; sek.: 7, 11.

Stropharia aeruginosa (Curtis) Quél. - Sh, na ziemi; a; X-XII 2008, X-XI 2009; sek.: 1, 3, 5, $7,8,9,11$.

Thelephora palmata (Scop.) Fr. - M, na ziemi; r; IX 2009; sek.: 8.

Th. terrestris Ehrh. - M, na gałązach pod Picea i Pseudotsuga; r; XII 2008; sek.: 11.

Trametes gibbosa (Pers.) Fr. - Sw, na pniaku; r; XII 2008, IV 2009; sek.: 1.

T. hirsuta (Wulfen) Lloyd - Sw, na gałęziach, kłodach, pniakach; a; V-VI,VIII-X, XII 2008, IIIIV 2009; sek.: 3, 4, 6, 9, 11, 12.

T. ochracea (Pers.) Gilb. \& Ryvarden - Sw, na gałęziach, kłodach, pniakach; a; V, XI-XII 2008, IV, X 2009; sek.: 3, 4, 6, 7, 9, 11.

T. versicolor (L.) Lloyd - Sw, na gałęziach, kłodach, pniakach; V, VIII, X, XII 2008, III-IV 2009; a; sek.: 2, 3, 4, 6, 7, 11.

Tremella mesenterica Retz. - P, na martwych gałęziach, na grzybach z rodziny Corticiaceae; n; XII 2008, XI 2009; sek.: 10-12.

Tricholoma scalpturatum (Fr.) Quél. - M, na ziemi pod Carpinus; n; IX, XI 2008, X-XI 2009; sek.: 3, 10, 11, 12.

Tubaria cf. conspersa (Pers.) Fayod - Sh, na ziemi, pod Quercus; r; XII 2008, XI 2009; sek.: 12. T. furfuracea (Pers.) Gillet - Sl, na gałązkach; a; XI-XII 2008, XI 2009; sek.: 4, 6, 8, 9, 10, 11, 12. Typhula fistulosa (Holmsk.) Olariaga [=Clavariadelphus fistulosus (Holmsk.: Fr.) Corner var. fistulosus] - Sw, na gałęzi, pod Alnus; r; XI 2009; sek.: 5, R.

Vuilleminia comedens (Nees) Maire - Sw, na gałęziach Quercus; r; V 2008; sek.: 12.

Xanthoporia radiata (Sowerby) Țura, Zmitr., Wasser, Raats \& Nevo [=Inonotus radiatus (Sowerby: Fr.) P. Karst.] - Sw, na kłodach, pod Alnus; n; X 2008; sek.: 3, 5.

Xerocomellus pruinatus (Fr. \& Hök) Šutara [=Xerocomus pascuus (Pers.) Krombh., X. chrysenteron (Bull.) Quel.] - M, na ziemi, pod Quercus, Fagus, Acer, Pseudotsuga; n; VIII-X 2008, VI, IX 2009; sek.: 8-12.

\section{DYSKUSJA}

Parki pałacowe, które do tej pory były obiektem badań mykologicznych (Lisiewska, Ratyńska 1984; Lisiewska, Rybak 1990; Lisiewska, Płaczek 1993; Bujakiewicz, Kujawa 2000), miały, oprócz części krajobrazowej (podlegającej zabiegom pielęgnacyjnym), także fragmenty o charakterze leśnym i to głównie w nich prowadzono obserwacje dotyczące występowania grzybów makroskopijnych. W parku w Małkocinie charakter leśny miał jedynie fragment sekcji 9. Jednak większość odnotowanych w parku grzybów (ponad 90\%), to gatunki występujace przede wszystkim w różnego typu zbiorowiskach leśnych. Gatunkami często notowanymi w grądach (Lisiewska 1965; Ławrynowicz 1973), a występującymi w parku są m.in.: Daedalea quercina, Gymnopus dryophilus, G. erythropus, Laetiporus sulphureus, Lepista nuda, Mycena filopes, M. vitilis i Pluteus cervinus. Choć drzew iglastych na badanym terenie rośnie niewiele, to znaleziono kilka gatunków grzybów wielkoowocnikowych związanych z borami (Friedrich 1984, 1985), m.in.: Boletus subtomentosus, Lactarius rufus, Mycena vulgaris, M. zephirus i Thelephora palmata. Na uwagę zasługuje również Amanita strobiliformis - gatunek ciepłolubny i wapniolubny, który występuje głównie w lasach liściastych południowej Europy, natomiast w Polsce 
jest rzadko notowany (Friedrich 2013; Kwiatkowska 2015). Jednak największą grupę stanowią w parku gatunki o szerokiej skali ekologicznej, spotykane zarówno w lasach liściastych, iglastych, jak i mieszanych (Friedrich 1985), m.in.: Hypholoma capnoides, H. fasciculare, Rickenella fibula i Stereum hirsutum.

W parku znaleziono tylko kilka gatunków grzybów występujących na łąkach, murawach i pastwiskach, m.in.: Agrocybe dura, A. pediades, Conocybe apala, Entoloma sericeum i Parasola plicatilis.

W miejscach po ogniskach, wśród węgla drzewnego lub na ziemi, rosły m.in.: Coltricia cinnamomea, Coprinellus angulatus, Pholiota highlandensis, Sphaerosporella brunnea i Hebeloma anthracophilum (w szczególności na starych wypaleniskach). Z kolei Anthracobia maurilabra i Pyronema omphalodes znalezione zostały w jeszcze świeżych wypaleniskach, gdzie zalegał popiół. Wiele gatunków obserwowano również na zwęglonych pniakach i gałęziach, m.in. Armillaria ostoyae, Pluteus nanus i Trametes ochracea.

Porównując dane mykologiczne z Gołuchowa, Radojewa, Turwi i Uniejowa (Lisiewska, Ratyńska 1984; Lisiewska, Rybak 1990; Lisiewska, Płaczek 1993; Bujakiewicz, Kujawa 2000), można stwierdzić, że bogactwo i różnorodność gatunkowa grzybów wielkoowocnikowych parku w Małkocinie jest większa niż w pozostałych parkach, choć zajmuje on dużo mniejszą powierzchnię (jest 3 razy mniejszy od parku w Radojewie i aż 33 razy mniejszy od parku w Gołuchowie, tab. 3). Park w Małkocinie ma najwięcej wspólnych gatunków grzybów z parkiem w Turwi (74 gatunki), natomiast najmniej z parkami w Uniejowie (54 gatunki) i Radojewie (55 gatunków). Wspólne gatunki to głównie saprotrofy nadrewnowe o szerokiej skali ekologicznej, m.in.: Bjerkandera adusta, Coprinellus micaceus, Ganoderma applanatum, Marasmius rotula, Mycena galericulata i Pluteus cervinus.

Tabela 3 - Table 3

Porównanie macromycetes parków wiejskich

Comparison of macromycetes of rural parks

\begin{tabular}{lccc}
\hline $\begin{array}{c}\text { Park } \\
\text { (Park) }\end{array}$ & $\begin{array}{c}\text { Liczba gatunków } \\
\text { grzybów } \\
\text { (Number of fungal } \\
\text { species) }\end{array}$ & $\begin{array}{c}\text { Liczba gatunków } \\
\text { grzybów wspólnych } \\
\text { z parkiem w Małkocinie } \\
\text { (Number of fungal } \\
\text { species shared with the } \\
\text { park in Małkocin) }\end{array}$ & $\begin{array}{c}\text { Powierzchnia parku } \\
\text { [ha] } \\
\text { (Park area } \\
\text { [ha]) }\end{array}$ \\
\hline Małkocin & 200 & - & 5 \\
Radojewo & 107 & 55 & 15 \\
Uniejów & 110 & 54 & 32 \\
Gołuchów & 135 & 59 & 165 \\
Turew & 177 & 74 & 21,86 \\
\hline
\end{tabular}




\section{PODSUMOWANIE}

Biota grzybów makroskopijnych parku w Małkocinie jest bogata i zróżnicowana. W ciągu dwóch lat obserwacji na obszarze 5 ha stwierdzono 200 gatunków grzybów wielkoowocnikowych, w tym 172 należy do Basidiomycota i 28 do Ascomycota. Ponadto odnotowano cztery gatunki z Myxomycota.

Na terenie parku zanotowano 11 gatunków znajdujących się na czerwonej liście grzybów wielkoowocnikowych w Polsce (Wojewoda, Ławrynowicz 2006). Do kategorii wymierających (E) należy Geastrum triplex, do narażonych (V) Rhizomarasmius setosus, do rzadkich (R): Amanita strobiliformis, Entoloma chalybaeum, Lentinus tigrinus, Mycena croccata, Polyporus tuberaster, Russula amoenolens i Typhula fistulosa, a do kategorii o nieokreślonym zagrożeniu (I): Coltricia cinnamomea i Pluteus plautus.

Wśród wyróżnionych grup bioekologicznych stwierdzono 157 gatunków saprotroficznych (77\% ogólnej liczby odnotowanych taksonów), w tym: 77 (38\%) saprotrofów nadrewnowych, 55 (27\%) saprotrofów napróchniczych i 25 (12\%) saprotrofów naściółkowych, ponadto 34 (17\%) gatunki mykoryzowe i 13 (6\%) pasożytniczych. Choć większość pasożytów na terenie parku wytwarzała pojedyncze owocniki, to kilka z nich, w szczególności Nectria cinnabarina i Armillaria ostoyae, rosło bardzo obficie i w wielu sekcjach parku, stanowiąc zagrożenie dla drzewostanu. Stosunkowo mały udział grzybów mykoryzowych może świadczyć o osłabieniu kondycji biologicznej drzew rosnących w parku i niesprzyjających rozwojowi grzybów tej grupy warunkach siedliskowych. $\mathrm{Na}$ uwagę zasługuje również grupa gatunków związanych z wypaleniskami, do której należą: Anthracobia maurilabra, Coprinellus angulatus, Hebeloma anthracophilum, Pholiota highlandensis, Pyronema omphalodes i Sphaerosporella brunnea.

Do najczęściej i najliczniej występujących gatunków w parku należą: Armillaria ostoyae, Bjerkandera adusta, Coprinellus disseminatus, Mycena galericulata, M. vitilis, Nectria cinnabarina, Stropharia aeruginosa, Tubaria furfuracea i Xylaria hypoxylon.

$\mathrm{Na}$ terenie parku w ciągu najbliższych lat najprawdopodobniej zajdą zmiany w składzie gatunkowym grzybów wielkoowocnikowych. Prace pielęgnacyjne, polegające między innymi na usuwaniu martwych kłód, pniaków i gałęzi oraz ściółki, wyeliminują wiele gatunków grzybów naściółkowych i nadrewnowych.

\section{LITERATURA}

Anonymous (2006): Inwentaryzacja dendrologiczna parku w Małkocinie (mskr.).

Bujakiewicz A., Kujawa A. (2000): Macrofungi of manorial park in Turew near Poznań. Acta Mycol., 35(2): 183-195.

Friedrich S. (1984): Mycoflora of Goleniowska Woods. Acta Mycol., 20(2): 173-207. 
Friedrich S. (1985): Macromycetes in the plant associations of the Goleniowska Woods. Acta Mycol., 21(1): 173-207.

Friedrich S. (2013): The occurrence of Amanita strobiliformis (Paulet ex Vittad.) Bertill. in Szczecin and its distribution in Poland. Acta Mycol., 48(1): 123-131.

Index Fungorum. http://www.indexfungorum.org (dostęp: 15.02.2017).

Jahn H., Nespiak A., Tüxen R. (1967): Pilzsoziologische Untersuchungen in Buchenwälder (Carici-Fagetum, Melico-Fagetum und Luzulo-Fagetum) des Wesergebirges. Mitt. Flor.-soz. Arbeitsgem. N.F., 11/12: 159-197.

Kalita K. (1977): Małkocin, woj. szczecińskie, gmina Stargard. Pałac, skrócona dokumentacja historyczna i opis wykonane na zlecenie Urzędu Wojewódzkiego, Wydziału Kultury i Sztuki Wojewódzkiego Konserwatora Zabytków w Szczecinie. Szczecin (mskr.).

Kondracki J. (2000): Geografia regionalna Polski. Ss. 440. Wyd. Nauk. PWN. Warszawa.

Kowalczyk A. (2006): Mapa z archiwum zasobów mapowych Pow. Ośr. Dokum. Geodezyjnej i Kartogr. Stargard Szczeciński (mskr.).

Kownas S. (1969): Przyroda powiatu stargardzkiego. [W:] Dopierała B. (red.). Z dziejów ziemi stargardzkiej: 43-54. Inst. Zachodniopomorski w Szczecinie, Monografie Regionalne nr 4. Poznań

Kwiatkowska J. (2015): Nowe stanowiska Amanita strobiliformis (Fungi, Agaricales) na Pomorzu. Fragm. Flor. Geobot. Polonica, 22(1): 118-121.

Lisiewska M. (1965): Udział grzybów wyższych w grądach Wielkopolski. - Higher fungi of the Querco-Carpinetum of the Wielkopolska province. Acta Mycol., 1(1): 169-268.

Lisiewska M. (2000): Analiza bioekologicznych grup macromycetes na tle zbiorowisk acidofilnych lasów dębowych. [W:] Lisiewska M., Ławrynowicz M. (red.). Monitoring grzybów: 27-51. Sekcja Mikologiczna PTB. Poznań-Lódź.

Lisiewska M., Płaczek U. (1993): Macromycetes zbiorowisk leśnych parku w Gołuchowie (województwo kaliskie). Bad. Fizjogr. nad Polską Zach., B, 42: 47-75.

Lisiewska M., Ratyńska H. (1984): Macromycetes na tle zbiorowisk leśnych parku w Radojewie koło Poznania. Bad. Fizjogr. nad Polską Zach., B, 35: 5-23.

Lisiewska M., Rybak M. (1990): Udział macromycetes w zespołach leśnych parku w Uniejewie. Bad. Fizjogr. nad Polską Zach., B, 40: 5-28.

Ławrynowicz M. (1973): Higher macroscopic fungi in the oak-hornbeam forests of the central Poland. Acta Mycol., 9(2): 133-204.

Mirek Z., Piękoś-Mirkowa H., Zając A., Zając M. (2002): Flowering plants and pteridophytes of Poland. A checklist. Ss. 442. W. Szafer Inst. of Bot., Pol. Acad. of Sci. Kraków.

Mityk J. (1969): Środowisko geograficzne. [W:] Dopierała B. (red). Z dziejów ziemi stargardzkiej: 9-42. Inst. Zachodniopomorski w Szczecinie, Monografie Regionalne nr 4. Poznań.

Rozporządzenie Ministra Środowiska z dnia 9 października 2014 r. w sprawie ochrony gatunkowej grzybów. Dz.U. 2014, poz. 1408.

Sienicka A., Kownas S. (1963): Parki wiejskie województwa szczecińskiego. Ss. 112. Szczec. Tow. Nauk., Wydz. Nauk Przyr.-Roln., Tom XVI, PWN, Oddział Poznański. Szczecin.

Sobisz Z., Truchan M. (2010): Zabytkowe parki podworskie Pomorza Środkowego. Ss. 281. Wyd. Nauk. Akad. Pomorskiej w Słupsku. Słupsk.

Starkel L. (1999): Geografia Polski. Środowisko Przyrodnicze. Ss. 593. Wyd. Nauk. PWN. Warszawa.

Wojewoda W., Ławrynowicz M. (2006): Red list of macrofungi in Poland. - Czerwona lista grzybów wielkoowocnikowych w Polsce. [W:] Mirek Z., Zarzycki K., Wojewoda W., Szeląg Z. (eds). Red list of plants and fungi in Poland. - Czerwona lista roślin i grzybów Polski: 53-70. W. Szafer Inst. of Bot., Pol. Acad. od Sci. Kraków.

Woś A. (1999): Klimat Polski. Ss. 185. Wyd. Nauk. PWN. Warszawa. 


\section{MACROMYCETES IN MAŁKOCIN PARK (NW POLAND)}

\section{Summary}

The objective of this paper is to explore the abundance and diversity of macrofungi species in the Małkocin park and to determine the participation and roles of bioecological groups of fungi found there. The park at Małkocin (5 ha) is situated in the north-eastern part of the village, some $36 \mathrm{~km}$ from Szczecin.

Mycological research was conducted from May 2008 to the end of November 2009, at intervals of 2-3 weeks. In total, 35 observations were completed. In order to enable a more precise identification of sites where given species occur within the park, it was divided into 12 sections. The respective sections differ in terms of criteria like size, composition of plant species, amounts of wood accumulated on the ground and frequency of maintenance.

In the Małkocin park, 200 species of macrofungi (including 172 species of Basidiomycota and 28 species of Ascomycota) and four Myxomycota species were found. Among them, 11 species are included on the red list of macrofungi in Poland (Wojewoda, Lawrynowicz 2006), e.g. Geastrum triplex (E), Rhizomarasmius setosus (V), Amanita strobiliformis (R), Entoloma chalybaeum (R), Mycena croccata (R), Polyporus tuberaster (R), Russula amoenolens (R) and Typhula fistulosa (R).

Among the identified bioecological groups, 157 saprotrophic species were found (77\% of the overall number of taxa found), including: 77 (38\%) wood-inhabiting saprotrophs, 55 (27\%) humus-inhabiting saprotrophs and 25 (12\%) litter-inhabiting saprotrophs, as well as 34 (17\%) mycorrhizal species and $13(6 \%)$ parasitic species. While the majority of parasites in the park produced single fruiting bodies, several, including particularly Nectria cinnabarina and Armillaria ostoyae, grew in large quantities and in many sections of the park, posing a threat to the tree stand. The relatively small proportion of mycorrhizal fungi may be indicative of the impaired biological condition of the trees growing in the park and the presence of site conditions which are unfavourable to the development of this group of fungi.

The species which occur there most frequently and most numerously include: Armillaria ostoyae, Bjerkandera adusta, Coprinellus disseminatus, Mycena galericulata, M. vitilis, Stropharia aeruginosa, Nectria cinnabarina, Tubaria furfuracea and Xylaria hypoxylon.

Another significant group of fungi is related to post-fire sites, and includes: Anthracobia maurilabra, Coprinellus angulatus, Hebeloma anthracophilum, Pholiota highlandensis, Pyronema omphalodes and Sphaerosporella brunnea. 